\title{
Histogram analysis for bedside respiratory monitoring in not critically ill preterm neonates: a proposal for a new way to look at the monitoring data
}

\author{
Amitava Sur ${ }^{1}$ (D) Anshuman Paria ${ }^{1}$ \\ Received: 27 April 2020 / Revised: 22 June 2020 / Accepted: 3 July 2020 / Published online: 8 July 2020 \\ (C) Springer-Verlag GmbH Germany, part of Springer Nature 2020
}

\begin{abstract}
Despite robust evidence in favour of maintaining optimal oxygen saturation targets in the preterm infants, the titration of oxygen is largely dependent on manual observations and transcription. Similarly, notwithstanding the gaining popularity of non-invasive modalities like high-flow nasal therapy, the practices of weaning and escalating support are largely individualized and based on point of care observations. These are often erroneous and lack objectivity. Histogram analysis from patient monitors is an easy and objective way of quantifying vital parameters and their trends. We review the technology and evidence available behind this practice.

Conclusions: Though there are no randomized controlled trials on this practice solely, we identify several quality improvement studies implementing this into practice with benefit. We also cite studies which have implemented histogram analysis in methodology, thus concluding that this is a useful clinical tool worth incorporating into clinical practice to reduce manual errors and bring more objectivity into decisions.
\end{abstract}

What is Known:

- The data from NeOProM (Neonatal Oxygenation Prospective Meta-analysis Collaboration study protocol) indicates that optimal saturation targets for preterm infants born $<28$ weeks should be between 91 and $95 \%$.

- The most "failsafe" way of maintaining strict compliance to these limits is automated oxygen titration but this is not widely used or available and manual transcription and monitoring are susceptible to error and fatigue.

What is New:

- Histogram analysis from patient monitors can provide intelligent data on respiratory monitoring and can be incorporated into algorithm to decide on weaning or escalation of respiratory support.

- With appropriate training, histogram monitoring by nursing staff can limit fatigue of manual recording of data.

Keywords Histogram · Oxygen saturation · Preterm · Non-invasive ventilation

Communicated by Daniele De Luca

Amitava Sur

Amitava.Sur@elht.nhs.uk

Anshuman Paria

dr.anshuparia@gmail.com

1 Department of Neonatology, Lancashire Women and Newborn Centre, East Lancashire Hospital NHS Trust, Casterton Avenue, Burnley BB10 2PQ, United Kingdom

$\begin{array}{ll}\text { Abbreviations } \\ \text { BPD } & \text { Bronchopulmonary dysplasia } \\ \text { CPAP } & \text { Continuous positive airway pressure } \\ \mathrm{FiO}_{2} & \text { Fraction of inspire oxygen } \\ \mathrm{GA} & \text { Gestational age } \\ \mathrm{HFNC} & \text { High-flow nasal cannula } \\ \mathrm{NIV} & \text { Non-invasive ventilation } \\ \mathrm{PCO}_{2} & \text { Partial pressure of carbon dioxide in blood } \\ \mathrm{PDSA} & \text { Plan Do Study Act } \\ \mathrm{QI} & \text { Quality improvement } \\ \mathrm{ROP} & \text { Retinopathy of prematurity } \\ \mathrm{RR} & \text { Respiratory rate } \\ \mathrm{SPO}_{2} & \text { Oxygen saturation }\end{array}$

Abbreviations

BPD Bronchopulmonary dysplasia

CPAP Continuous positive airway pressure

$\mathrm{FiO}_{2} \quad$ Fraction of inspire oxygen

GA Gestational age

HFNC High-flow nasal cannula

NIV Non-invasive ventilation

$\mathrm{PCO}_{2}$ Partial pressure of carbon dioxide in blood

PDSA Plan Do Study Act

QI Quality improvement

ROP Retinopathy of prematurity

$\mathrm{SPO}_{2} \quad$ Oxygen saturation 


\section{Respiratory support for the preterm infant-changing paradigm}

The last decade in neonatology has seen a change in principles of respiratory care for the preterm infant. The two major shifts of practice have been in use of early noninvasive ventilation (NIV) as respiratory support and altered saturation targets for optimal oxygenation. While CPAP has been the most commonly used form of NIV in the past, high-flow nasal cannula (HFNC) has emerged as the preferred option for many neonatal units [1]. The major criticism around HFNC, in spite of perceived improved patient comfort, has been the uncertainty around consistency in delivering PEEP. Nasal intermittent positive pressure ventilation (NIPPV) has been reported to have improved rates of success in extubation when compared with CPAP [2]. The two main forms of NIPPV commonly used are bi-level NIPPV and ventilator-driven NIPPV (CMV), the latter having the advantage of being able to deliver higher peak inspiratory pressures and shorter inspiratory times [3]. Nasal high-frequency oscillatory ventilation (HFOV) and NIV-NAVA (neurally adjusted ventilatory assist) are other, albeit less commonly used, modalities of NIV. Nasal HFOV has been shown to have superior clearance of $\mathrm{CO}_{2}$ and reduce risk of intubation in preterm infants in a recent meta-analysis when compared with common modes like CPAP or bi-level NIPPV [4]. NAVA improves synchrony in patients with respiratory support by detecting the electrical activity of the diaphragm and may offer potential benefits in neonatal ventilation. Again, it has been shown to be superior to CPAP in facilitating extubation in preterm infants in small studies [5]. So, it seems that a synchronised modality of consistent pressure delivery might be superior to conventional modalities of NIV, but their use across neonatal units is still limited. Irrespective of the modality, subsequent weaning of non-invasive support is not evidence based and requires streamlining based on physiology. Current guidelines are at best a compendium of expert consensus opinions [1]. Decision to wean is generally influenced by regimented weight-based approach, perceived $\mathrm{FiO}_{2}$ requirement, snapshot counting of respiratory rate (RR) and clinically examined work of breathing. Measured $\mathrm{PCO}_{2}$ in blood gas analysis is also often used to guide the weaning process but it is a poor physiological reflection of pressure requirement.

Optimal saturation targeting for the preterm infants has been long-standing debate with widely variable practices. The data from the NeOProM meta-analysis has clearly demonstrated less risk of mortality and necrotizing enterocolitis when saturation targets are between 91 and $95 \%$ as compared with lower targets [6]. Preterm infants with evolving or established chronic lung disease are known to have swinging saturations; spending a sizable proportion of time outside saturation limits with cumulatively unacceptable periods of hypoxia and hyperoxia. While prolonged periods of hypoxia can contribute to increased risk of mortality and necrotising enterocolitis, hyperoxia has been associated with retinopathy of prematurity and chronic lung disease [6]. Sustained periods of hypoxia are also known to increase risk of pulmonary hypertension. Manual transcribing of saturations by nursing staff is still the gold standard for bedside monitoring in neonatal units but they tend to underestimate these fluctuations and time spent outside desirable range [7] and is also associated with considerable alarm fatigue. While closed loop oxygen feedback systems can alleviate some of these problems while on invasive ventilation, infants of non-invasive support continue to have such episodes. A recent study on use of automated oxygen control via IntellO2 has shown significantly improved control in saturation targets in babies on HFNC [8], but again this is not used in wider practice and is still limited to research. In summary, although more preterm neonates are being supported with NIV, tight control of saturations and objective escalation and de-escalation are yet to be optimized. Data from electronic patient monitoring can provide an important missing link in this regard.

\section{Histograms-bringing objectivity into monitoring}

Histograms are a graphical way of representing patient's measurements over an extended time period. It basically answers the question: "For how much of a certain period of time was my patient within or outside a certain range of values?" For respiratory monitoring of preterm neonates, we rely on a set of clinical parameters and observations to remain within prespecified ranges, e.g., saturation between 91 and 95\%, and histogram analysis allows us to observe this. Generally, it is represented as a cluster of bars, with each bar representing time spent within a particular time interval. The picture below (Fig. 1a) is an example of a saturation histogram where the $X$ axis represents the parameter range and $Y$-axis the distribution. Each blue bar represents the percentage of time spent in the range. Histograms can be used for both real-time data and trended data like heart rate and respiratory rate. Being a numerical and graphical representation, they allow us to easily appreciate effects of any intervention by studying a change in pattern.

\section{Learning from the patient monitor}

All standard pulse oximeters and monitors will have the algorithm to produce histograms, but in this piece we will focus on the Philips IntelliVue monitors. The inbuilt pulse 

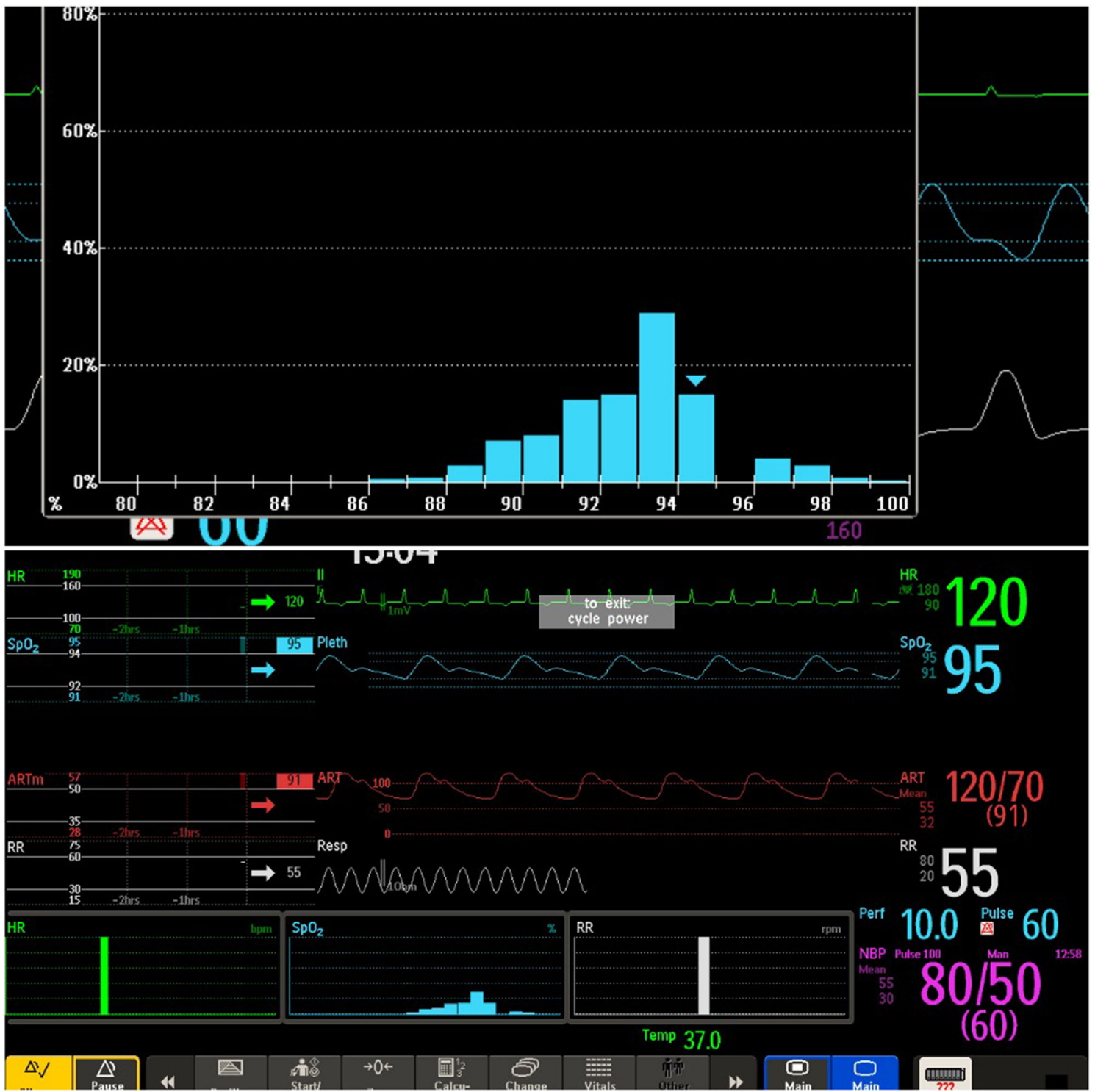

Fig. 1 a An example of a saturation histogram. bThe "3 histogram view" showing HR, SPO2 and RR distribution

oximetry module (M1020B \#A01) uses a motion-tolerant signal processing algorithm, based on Fourier Artefact Suppression Technology (FAST). It provides four measurements: oxygen saturation of arterial blood $\left(\mathrm{SpO}_{2}\right)$, plethysmograph waveform, pulse rate and perfusion indicator. The histogram feature can be selected from the main screen of the monitor and it yields two types of data: real time and trended. The $\mathrm{SpO}_{2}$ histogram is calculated over 12 or $24 \mathrm{~h}$ with a $1 \mathrm{~s}$ real-time sampling rate. For parameters like respiratory rate and heart rate, the data is built over similar time period but with a sampling rate of 1 or $5 \mathrm{~min}$. For histogram analysis of any parameter, the bars in the foreground (blue) show the percentage of time the values fall into each unit on the scale. The bars in the background (shaded area) show the cumulative percentage-of-time value, which results from adding each of the foreground bars to the sum of those to its left. The vertical axis shows the percentage of time.

The monitor can be customized so that maximum patient information is displayed on the same screen allowing the clinician to obtain a comprehensive picture of the variability and median values. This can be through the " 3 histogram view" (Fig. 1b) which also displays the histogram analysis of saturation, $\mathrm{RR}$ and $\mathrm{HR}$ over a chosen time period thus providing a more objective idea of the trend.

It is worthwhile noting the fourth parameter displayed on screen, although we will not discuss it in details - perfusion numeric (Perf). The accuracy of the readings for this oximeter is well validated for perfusion values between 0.3 and 1 .

Figure 2 depicts the real example of a patient with suboptimal histogram with $29 \%$ of the time in the last $12 \mathrm{~h}$ spent below $90 \% \mathrm{SPO}_{2}$. 


\section{Limitations of histogram technology and other non-invasive measures of hypoxemic respiratory failure (HRF)}

The review of the technology obviously brings to front certain limitations. For example, the data will be influenced by sampling time and relative stability of the patient. For a critically ill infant with rapid and continuous change in parameters, a stable consistent histogram will not be available, and decisions based on that risk being erroneous. Also, other parameters like delivered mean airway pressure (MAP), (which can be impacted by the leak) and physiological changes like temperature and pain perception can alter respiratory and heart rate.

Although monitoring based on $\mathrm{PaO}_{2}$ is the gold standard for HRF, certain non-invasive trends have been used successfully like oxygen saturation index, respiratory severity score, $\mathrm{SPO}_{2} / \mathrm{FiO}_{2}$ ratio $(\mathrm{S} / \mathrm{F})$ and transcutaneous monitoring of $\mathrm{PO}_{2}\left(\mathrm{TcPO}_{2}\right)$. Detailed review of these is beyond the scope of this article. But it is worth mentioning that monitoring based on $\mathrm{SPO}_{2}$ values can often be fallacious as $\mathrm{SPO}_{2}$ values are affected by various factors including fetal $\mathrm{Hb}$. In a large ARDS network trial, $\mathrm{S} / \mathrm{F}$ of 315 correlated well with $\mathrm{PaO}_{2} / \mathrm{FiO}_{2}$ of 300 [9]. $\mathrm{TcPO}_{2}$ has been recommended by various studies and its feasibility has been well established in adult studies. $\mathrm{TcPO}_{2}$ might be an added advantage in infants without arterial access as its values can have good correlation with $\mathrm{pAO}_{2}$ if the sensor is pre-warmed. A recent study which combined a new fluorescent quenching technique of monitoring $\mathrm{PO}_{2}$ with pulse oximetry has shown good feasibility and minimal value drift [10]. Adding this to histogram data in patient monitors might bring more accuracy and less bias to monitoring.

\section{What is available in current literature on use of histogram}

Although it is a relatively recent addition to the clinical repertoire of preterm respiratory monitoring, several groups have already reported on the utility of using this. We conducted a search on medical databases namely Medline, Ovid and CINAHL with the Mesh terms (Histogram OR Histogram analysis OR histogram monitoring OR oxygen saturation histogram) AND (neonat* OR preterm OR prematu*). Search yielded 7707 articles. After removing duplications and applying relevant search filters, 45 articles and conference papers including dissertations were screened and 6 full-text articles were included for qualitative synthesis (Table 1).

It was not possible to provide a meta-analysed data as the use of histogram in these studies were not always the primary intervention, rather in certain instances just a part of methodological tool kit. But the range of time spent outside saturation target that has been deemed as significant in the studies ranges from 5 to $20 \%$ (mean $10 \%)$. The lower acceptable saturation limit for this assessment ranges from 81 to $90 \%$ (mean $86 \%$ ). Based on the review of literature, the authors propose that $>20 \%$ time spent below $91 \%$ or above $95 \%$ is unacceptable and should lead to clinical intervention. From the physiological point it also seems rational to consider $>20 \%$ time spent with respiratory rate $>80 / \mathrm{min}$ to be unacceptable. Based on the above, the authors propose the following algorithm for titration of non-invasive respiratory support based on histogram. This algorithm is just a physiological extrapolation and current practice in the authors' unit.

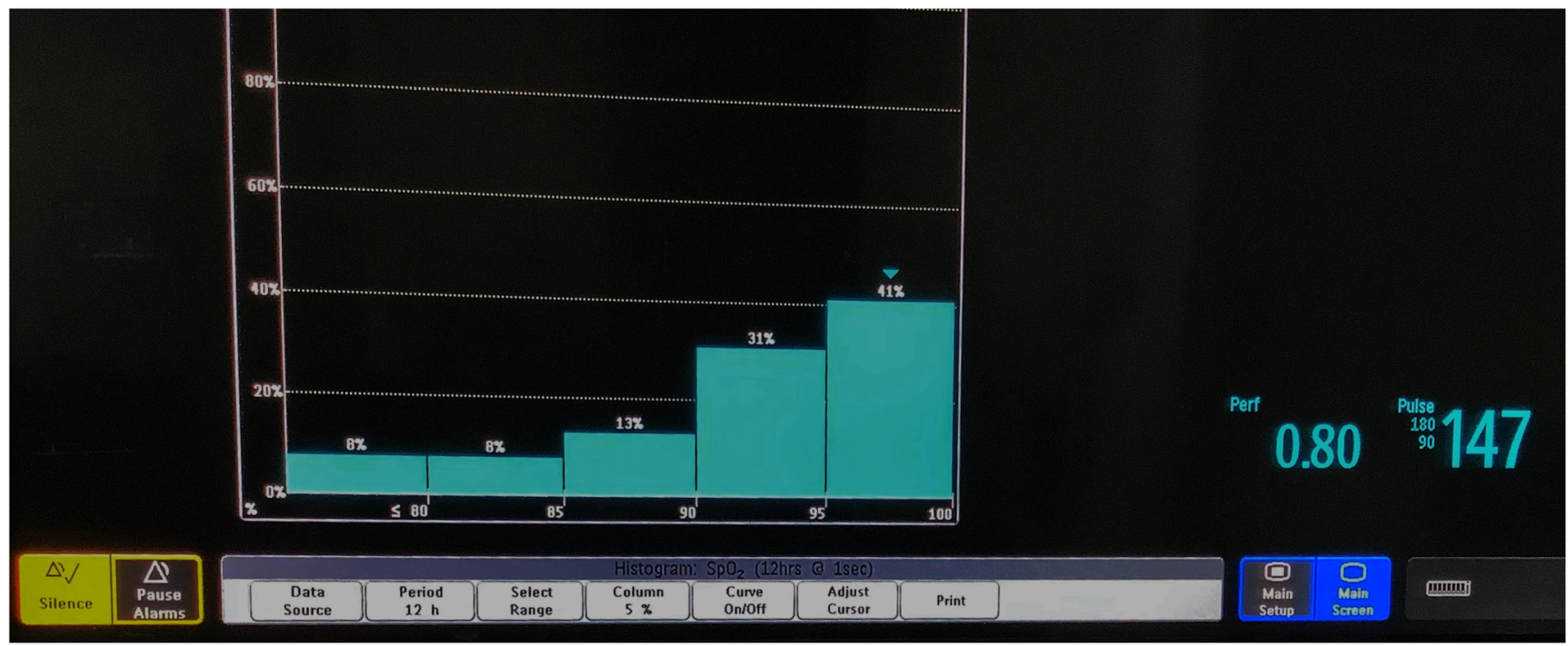

Fig. 2 Real time example of a suboptimal histogram with $29 \%$ of the time spent $<90 \% \mathrm{SPO}_{2}$ 
Table 1 Summary of selected articles on histogram analysis

\begin{tabular}{|c|c|c|c|}
\hline Study & Description & Results & Conclusions \\
\hline $\begin{array}{l}\text { Gentle et al. (2020) } \\
\quad[11]\end{array}$ & $\begin{array}{l}\text { QI initiative to implement histogram } \\
\text { monitoring into daily clinical rounds and } \\
\text { training of residents, nursing staff and } \\
\text { respiratory therapist in histogram analysis. } \\
\text { Aim: To reduce rate of death/severe ROP in } \\
<29 \text { weeks and improve time spent within } \\
\text { target } \mathrm{SPO}_{2} \text { limit } 90-95 \% \text {. }\end{array}$ & $\begin{array}{l}\text { In infants }<29 \text { weeks' gestation }(n=518) \text {, } \\
\text { the rate of death or severe retinopathy of } \\
\text { prematurity prior to hospital discharge } \\
\text { decreased from } 32.1 \text { to } 18.0 \% \text {. Time within } \\
\text { goal saturations }(90-95 \%) \text { increased from } \\
48.7 \text { to } 57.6 \%(p<0.0001) \text {. }\end{array}$ & $\begin{array}{l}\text { The study outlines a QI process and states } \\
\text { the importance of multiple PDSA } \\
\text { cycles and training at multiple levels to } \\
\text { influence sustainable change. }\end{array}$ \\
\hline $\begin{array}{l}\text { Borenstein-Levin } \\
\quad \text { et al. (2019) [12] }\end{array}$ & $\begin{array}{l}\text { Analysis of } 6000 \text { histograms from } 73 \text { infants } \\
\text { of mean GA } 28 \pm 3 \text { weeks was carried out } \\
\text { and categorized into } 5 \text { types based on } \\
\text { cumulative time spent below } \mathrm{SPO}_{2} 81 \% \\
\text { and number of bars between cumulative } 10 \\
\text { and } 90 \% \text {. }\end{array}$ & $\begin{array}{l}\text { Types } 1-2 \text { were classified as stable with cu- } \\
\text { mulative time spent }<81 \% \text { being } 0 \% \text {. } \\
\text { Types } 3-5 \text { were classified as unstable with } \\
\text { times spent }<81 \% \text { being }<5 \%, 5-9 \% \text { and } \\
>10 \% \text { respectively. } \\
\text { Infants developing unstable histograms during } \\
\text { the first week received longer ventilatory } \\
\text { support (median [IQR], } \\
101[66] \text { vs. } 62[28] \text { days) and supplemental } \\
\text { oxygen }(62.5[72] \text { vs. } 40.5[40] \text { days), } \\
\text { and more were on ventilatory support at } \\
40 \text { weeks } \\
(7 / 15 \text { vs. } 0 / 10) \text {. }\end{array}$ & $\begin{array}{l}\text { Documentation of histogram analysis can } \\
\text { lead to early identification of infants at } \\
\text { risk of prolonged respiratory support. }\end{array}$ \\
\hline $\begin{array}{l}\text { Warburton et al. } \\
\text { (2019) [13] }\end{array}$ & $\begin{array}{l}\text { To examine the correlation between interval } \\
\text { vital signs recorded by nursing staff and } \\
\text { continuous monitor recordings, and to } \\
\text { determine whether aggregated monitor } \\
\text { recordings could better predict impending } \\
\text { escalation of respiratory support in } \\
\text { premature infants. } \\
\text { Ninety-four infants with median GA } 32 \text { weeks } \\
\text { were enrolled and events of hypoxia } \\
(<90 \%) \text { and tachypnea (RR }>70 / \text { min) were } \\
\text { recorded. Correlation between nursing } \\
\text { records and monitor events was analysed. } \\
\text { Philips IntelliVue MP50 Neonatal monitors } \\
\text { were used for recording. }\end{array}$ & $\begin{array}{l}\text { Infants with monitor-recorded hypoxia for }> \\
5 \% / \text { day }(p<0.0001) \text { or tachypnea for }> \\
30 \% / \text { day }(p<0.0001) \text { were more likely to } \\
\text { require an increase in respiratory support } \\
\text { within the next } 3 \text { days. } \\
\text { The overall correlation coefficient between } \\
\text { nursing and monitor records was } 0.507 \text { for } \\
\text { hypoxia events and } 0.431 \text { for tachypnea } \\
\text { (RR }>70) \text {. } \\
\text { For infants who had escalation of support, } \\
\text { nursing documentation of hypoxia recorded } \\
\text { by monitors was not present in } 46.6 \% \\
(p<0.0001) \text {, and tachypnea in } 27.8 \% \\
(p<0.0001) \text { of infants. }\end{array}$ & $\begin{array}{l}\text { Manual documentation of data points for } \\
\text { respiratory events were less in number } \\
\text { and less accurate as compared with that } \\
\text { generated from monitors. } \\
\text { Histogram analysis of } \mathrm{SPO}_{2} \text { and RR could } \\
\text { predict escalation of respiratory } \\
\text { support. }\end{array}$ \\
\hline $\begin{array}{l}\text { Mascoll-Robertson } \\
\text { et al. (2016) [14] }\end{array}$ & $\begin{array}{l}\text { Analysis of } 24 \mathrm{~h} \text { histograms in } 31 \text { infants } \\
\text { between } 24 \text { and } 32 \text { weeks to predict failure } \\
\text { of transition from CPAP or HFNC. } \\
\text { Hypothesis: Infants with } \geq 15 \% \text { of time spent } \\
\text { with } \mathrm{SpO}_{2}<86 \% \text { before transitioning from } \\
\text { CPAP or high-flow nasal cannula (HFNC) } \\
\text { to low-flow nasal cannula, oxyhood or } \\
\text { room air were more likely to fail. }\end{array}$ & $\begin{array}{l}\text { Twenty-four infants transitioned successfully, } \\
\text { but } 7 \text { failed. Two of } 7(28.6 \%) \text { who failed } \\
\text { experienced } \mathrm{SpO}_{2}<86 \% \geq 15 \% \text { of the time } \\
\text { pre-transition compared with none in the } \\
\text { success group }(p=.045) \text {. The failure group } \\
\text { experienced } \mathrm{SpO}_{2}<86 \% 10.7 \pm 11.9 \% \text { of } \\
\text { time pre-wean compared with } 3.3 \pm 4.7 \% \text { of } \\
\text { time in the success group }(p=.02) .\end{array}$ & $\begin{array}{l}\text { Histogram analysis can predict readiness } \\
\text { for transition from respiratory support. } \\
\text { Limitation: Small observational study. }\end{array}$ \\
\hline $\begin{array}{l}\text { Soonsawad et al. } \\
\text { (2016) [15] }\end{array}$ & $\begin{array}{l}\text { RCT comparing strategies to wean off CPAP } \\
\text { for preterm infants. One hundred one } \\
\text { infants }<32 \text { weeks who met criteria to wean } \\
\text { off CPAP were randomized to HFNC or } \\
\text { reduction of pressure on CPAP to } 4 \mathrm{~cm} \\
\mathrm{H}_{2} \mathrm{O} \text {. }\end{array}$ & $\begin{array}{l}\text { Histogram analysis was used as methodology } \\
\text { to label which infants were "stable" on } \\
\mathrm{CPAP} \text { to wean. If time spent in } \mathrm{SPO}_{2}<85 \% \\
\text { was }<5 \% \text {, } \\
\text { they were deemed stable. }\end{array}$ & $\begin{array}{l}\text { Though not used as primary intervention, } \\
\text { this study also used histogram analysis } \\
\text { as background assessment of } \\
\text { respiratory support. }\end{array}$ \\
\hline $\begin{array}{l}\text { Bizzaro et al. } \\
\text { (2014) [16] }\end{array}$ & $\begin{array}{l}\text { Evaluation of oxygen exposure among very } \\
\text { low birth weight infants. Infants were } \\
\text { assigned target saturation ranges and signal } \\
\text { extraction technology and histogram } \\
\text { analysis was implemented to temporally } \\
\text { quantify achievement of these ranges. } \\
\text { Outcome analysis included BPD/death/ROP. } \\
\text { Target saturations were altered from } 88-96 \% \\
\text { to } 85-93 \% \text { for those requiring supplemental } \\
\text { oxygen and from } 88-100 \% \text { to } 85-100 \% \text { for } \\
\text { those in room air. } \\
\text { Target was to maintain all infants within } \mathrm{SPO}_{2} \\
\text { target range for }>75 \% \text { of time. }\end{array}$ & $\begin{array}{l}\text { Decreased odds of severe ROP (adjusted odds } \\
\text { ratio (OR): } 0.41 ; 95 \% \text { confidence interval } \\
\text { (CI): } 0.24-0.72 \text { ) and ROP requiring surgery } \\
\text { (adjusted OR 0.31; } 95 \% \text { CI: } 0.17-0.59 \text { ) } \\
\text { post-initiative. }\end{array}$ & $\begin{array}{l}\text { Quality improvement initiative outlining } \\
\text { importance of staff education in } \\
\text { outcome measures. } \\
\text { The accepted targets were before the } \\
\text { NeOProM data so were different from } \\
\text { current accepted standards. }\end{array}$ \\
\hline
\end{tabular}


Protocol driven; histogram guided weaning from non-invasive respiratory support

General rules of HFNC weaning:

1. Wean flow in steps of 0.5 LPM in babies $<1.5 \mathrm{~kg} /$ babies with CLD. Wean flow by 1 LPM in all other babies.

2. Do not decrease flow until $\mathrm{FiO}_{2}<30 \%$ in preterm babies, and $<40 \%$ in babies with established CLD.

3. Change $\mathrm{FiO}_{2}$ in steps of 3-5\%.

4. An attempt will be made to wean according to point 1,2-as long as the histogram is also favourable to weaning (see charts below).

Chart: specific guidance about histogram based flow and $\mathrm{FiO}_{2}$ titration:

$\%$ of time spent in the Percentage of time spent Percentage of last 12-24 h with with $\mathrm{SPO}_{2}$ below $90 \%$ time spent with saturation/RR

$\mathrm{SPO}_{2}$ above 95\%

$>20 \%$

$\mathrm{RR}>80$ for $>20 \%$ of the time (severe tachypnoea $\pm \uparrow$ work of breathing)

$$
\begin{gathered}
>\mathbf{2 0 \%} \\
\uparrow \text { Flow by } \\
1-2 \\
\text { LPM } \neq
\end{gathered}
$$$$
<20 \%
$$
$\uparrow$ Flow by $1-2$ LPM

\begin{tabular}{|c|c|c|}
\hline & $\begin{array}{c}F \\
\uparrow \mathrm{FiO} 2 \text { by } \\
3-5 \%\end{array}$ & \\
\hline $\begin{array}{l}\mathrm{RR} \sim 60-80 \text { for }>20 \% \\
\text { of the time } \\
\text { (moderate } \\
\text { tachypnoea only) }\end{array}$ & $\begin{array}{c}\uparrow \text { Flow by } \\
\text { at } 0.5-1 \\
\text { LPM } \neq \\
\uparrow \mathrm{FiO}^{2} \text { by } \\
3-5 \%\end{array}$ & $\begin{array}{c}\text { Do not wean } \\
\text { flow/wean } \\
\text { cautious- } \\
\text { ly* }\end{array}$ \\
\hline $\begin{array}{l}\mathrm{RR}>60 \text { for }<20 \% \text { of } \\
\text { the time (no } \\
\text { tachypnoea) }\end{array}$ & $\begin{array}{c}\text { Wean flow } \\
\text { cau- } \\
\text { tiously* } \\
\uparrow \text { FiO2 by } \\
3-5 \%\end{array}$ & $\begin{array}{l}\text { Wean } \\
\text { (ideal for } \\
\text { weaning) }\end{array}$ \\
\hline
\end{tabular}
Wean $\mathrm{FiO} 2$ by $3-5 \%$

Following successful weaning of flow, the baby should spend $<20 \%$ of time with $\mathrm{RR}>60$ and need $<5 \%$ increase in $\mathrm{FiO}_{2}$. If histogram deteriorates significantly after wean, consider going back even if $\mathrm{PCO}_{2}$ is normal. If babies spend 10-20\% time with both saturation $<90 \%$ and $>95 \%$, $\uparrow$ flow \pm marginal reduction in $\mathrm{FiO}_{2}$ in $\mathrm{HFNC}$. Consider other forms of non-invasive respiratory support if $\mathrm{FiO} 2>50 \%$.

\# Equivalent changes in NIPPV $=2-4 \mathrm{~cm}$ PIP. If no improvement, then recruit further, by increasing PEEP by $1 \rightarrow$ increasing rate by $2-5 / \mathrm{min} \rightarrow$ increase in inspiratory time by 0.1 to the maximum to $1 \mathrm{~s}$ (decrease rate to 30). Further recruitment/escalation to invasive modality may be needed depending on work of breathing and CXR images.

\# Equivalent changes in NIPPV $=1-2 \mathrm{~cm}$ PIP. If on CPAP, consider increasing CPAP by $1 \mathrm{~cm}$.

\section{Conclusion}

In this article, we highlight the difficulties and resulting inaccuracies in manual transcription of vitals for respiratory monitoring in the NICU. In light of this and the importance of tight control of saturations in this vulnerable cohort of infants, often with prolonged respiratory support, we have discussed how patient monitors can provide us with objective data. We have also provided a clinical range of acceptable deviation from target range beyond which a clinician should ideally look to intervene.

Histogram is not a new tool and is a well-accepted statistical modality of data analysis, but as a clinical decision-making aid it is relatively recent. Small number of studies and the emphasis on preterm population only are the limitations of the review. The latter is understandable as the effects of hypoxia and hyperoxia are more pronounced and definitive on the preterm population and hence of greater clinical concern. The authors are not aware of any previous article which reviews the technology and evidence behind histogram analysis and its application in the neonatal intensive care unit.

Author contributions AS and AP conceptualized the article. AP and AS conducted the background literature search. AS devised the manuscript and both authors agree to the formatting and contents.

\section{Compliance with ethical standards}

Conflict of interest The authors declare that they have no conflict of interest.

Ethical approval This article does not contain any studies with human participants or animals performed by any of the authors.

\section{References}

1. Roehr C, Yoder B, Davis P, Ives K (2016) Evidence support and guidelines for using heated, humidified, high-flow nasal cannulae in neonatology. Clin Perinatol 43(4):693-705

2. Lemyre B, Davis PG, de Paoli AG, Kirpalani H (2017) Nasal intermittent positive pressure ventilation (NIPPV) versus nasal continuous positive airway pressure (NCPAP) for preterm neonates after extubation. Cochrane Database Syst Rev 2

3. Roberts CT, Davis PG, Owen LS (2013) Neonatal non-invasive respiratory support: synchronised NIPPV, non-synchronised NIPPV or bi-level CPAP: what is the evidence in 2013? Neonatology. 104:203-209

4. Li J, Li X, Huang X, Zhang Z (2019) Noninvasive high-frequency oscillatory ventilation as respiratory support in preterm infants: a meta-analysis of randomized controlled trials. Respir Res 20:58

5. Lee BK, Shin SH, Jung YH, Kim EK, Kim HS (2019) Comparison of NIV-NAVA and NCPAP in facilitating extubation for very preterm infants. BMC Pediatr 19:298

6. Askie Lisa M, Darlow Brian A, Neil F et al (2018) Association between oxygen saturation targeting and death or disability in extremely preterm infants in the Neonatal Oxygenation Prospective Meta-analysis Collaboration. JAMA. 319(21):2190-2201

7. Ruiz TL, Trzaski JM, Sink DW, Hagadorn JI (2014) Transcribed oxygen saturation vs oximeter recordings in very low birth weight infants. J Perinatol 34(2):130-135

8. Reynolds PR, Miller TL, Volakis LI et al (2019) Randomised crossover study of automated oxygen control for preterm infants receiving nasal high flow. Arch Dis Childhood - Fetal Neonatal Ed 104: F366-F371

9. Rice TW, Wheeler AP, Bernard GR, Hayden DL, Schoenfeld DA, Ware LB, National Institutes of Health, National Heart, Lung, and Blood Institute ARDS Network (2007) Comparison of the SpO2/ 
FIO2 ratio and the $\mathrm{PaO} 2 / \mathrm{FIO} 2$ ratio in patients with acute lung injury or ARDS. Chest 132(2):410-417

10. van Weteringen W, Goos TG, van Essen T, Ellenberger C, Hayoz J, de Jonge RCJ, Reiss IKM, Schumacher PM (2020) Novel transcutaneous sensor combining optical tcPO2 and electrochemical tcPCO2 monitoring with reflectance pulse oximetry. Med Biol Eng Comput 58(2):239-247

11. Gentle S, El-Ferzli G, Winter L et al (2019) Oxygen saturation histogram monitoring to reduce death or retinopathy of prematurity: a quality improvement initiative. J Perinatol 40:163-169. https:// doi.org/10.1038/s41372-019-0486-7

12. Borenstein-Levin L, Konikoff L, Solimano A (2019) Clinical quantification of $\mathrm{SpO} 2$ instability using a new histogram classification system: a clinical study. Pediatr Res

13. Warburton A, Monga R, Sampath V, Kumar N (2019) Continuous pulse oximetry and respiratory rate trends predict short-term respiratory and growth outcomes in premature infants. Pediatr Res 85:494-501

14. Mascoll-Robertson KK, Viscardi RM, Woo HC (2016) The objective use of pulse oximetry to predict respiratory support transition in preterm infants: an observational pilot study. Respir Care 61(4): 416-422

15. Soonsawad S, Tongsawang N, Nuntnarumit P (2016) Heated humidified high-flow nasal cannula for weaning from continuous positive airway pressure in preterm infants: a randomized controlled trial. Neonatology. 110(3):204-209

16. Bizzaro M, Katz FY, Shabanova V (2014) Temporal quantification of oxygen saturation ranges: an effort to reduce hyperoxia in the neonatal intensive care unit. J Perinatol 34:33-38

Publisher's note Springer Nature remains neutral with regard to jurisdictional claims in published maps and institutional affiliations. 